\title{
PENGARUH PENGGUNAAN SERAT HIGH DENSITY POLYETHYLENE (HDPE) PADA CAMPURAN BETON TERHADAP KUAT TARIK BETON
}

\author{
Erwin Rommel ${ }^{1}$, Yunan Rusdianto ${ }^{2}$, Anita Kurniati ${ }^{3}$ \\ ${ }^{1,2,3)}$ Jurusan Teknik Sipil Fakultas Teknik Universitas Muhammadiyah Malang \\ ${ }^{3)}$ Alumni Teknik Sipil FT-UMM \\ email : erwin67pro@yahoo.com
}

\begin{abstract}
Research on the addition of HDPE fibers in normal concrete is intended to determine the relationship between the percentage of variation of fiber addition of HDPE to the workability, tensile strength and determine the pattern of deployment of fiber in concrete. The addition of HDPE fibers is intended to increase the tensile strength of concrete. The concrete was mixed using gresik cement type PPC, sand with the gradation limits zone 2, the gravel with a maximum grain size of 20 $\mathrm{mm}$, and HDPE fibers with a width of $0.5 \mathrm{~cm}$ and $2.5 \mathrm{~cm}$ long. Variations in the addition of HDPE fibers are $0 \%, 1 \%, 2 \%, 3 \%, 4 \%, 5 \%, 6 \%, 7 \%, 8 \%, 9 \%, 10 \%$ of the volume of the mixture. Tensile strength testing performed with a cylindrical test piece with a diameter of $150 \mathrm{~mm}$ and $300 \mathrm{~mm}$ height at the age of 28 days of the test object. Tensile strength of concrete data analysis using regression analysis. The results showed that the addition of HDPE fibers can increase the value of tensile strength sides. There is a strong pull on the sides of the optimum levels of $4 \%$ with a tensile strength of $2.86 \mathrm{MPa}$ increased by $18 \%$.
\end{abstract}

Key words: Concrete, HDPE fibers, Tensile strength

\begin{abstract}
Abstrak
Penelitian tentang penambahan serat HDPE di beton normal dimaksudkan untuk mengetahui hubungan antara persentase variasi penambahan serat dari HDPE untuk pengerjaan, kekuatan tarik dan menentukan pola penyebaran serat dalam beton. Penambahan serat HDPE dimaksudkan untuk meningkatkan kekuatan tarik beton. Beton dicampur menggunakan semen gresik Jenis PPC, pasir dengan batas gradasi zona 2, kerikil dengan ukuran butir maksimum $20 \mathrm{~mm}$, dan serat HDPE dengan lebar $0,5 \mathrm{~cm}$ dan $2,5 \mathrm{~cm}$. Variasi penambahan serat HDPE adalah $0 \%, 1 \%, 2 \%, 3 \%, 4 \%, 5 \%, 6 \%, 7 \%, 8 \%$, $9 \%, 10 \%$ dari volume campuran. Kekuatan tarik pengujian dilakukan dengan benda uji berbentuk silinder dengan diameter $150 \mathrm{~mm}$ dan tinggi $300 \mathrm{~mm}$ pada umur 28 hari dari benda uji. Kekuatan tarik dari analisis data konkret dengan menggunakan analisis regresi. Hasil penelitian menunjukkan bahwa penambahan serat HDPE dapat meningkatkan nilai sisi kekuatan tarik. Ada tarik yang kuat di sisi tingkat optimum dari 4\% dengan kekuatan tarik 2.86 MPa meningkat sebesar 18\%
\end{abstract}

Kata kunci: Beton, serat HDPE, kekuatan tarik

\section{PENDAHULUAN}

Beton merupakan fungsi dari bahan penyusunya yang terdiri dari bahan semen hidrolik (Portland cement), agregat kasar, agregat halus, air dan bahan tambah (admixture atau additive). Beton juga mempunyai beberapa kelebihan dibandingkan bahan konstruksi yang lain, diantaranya mempunyai kuat tekan yang besar, tahan terhadap api, mudah dibentuk, tidak diperlukan keahlian khusus dalam pembuatannya, dan bahan bakunya mudah untuk didapatkan, sehingga beton unggul dari segi biaya.
Karena itu, saat ini beton menjadi pilihan utama bagi masyarakat dalam mendirikan suatu bangunan. Namun beton juga dikenal sebagai material yang lemah terhadap tarik dan getas (tidak daktail) dibandingkan dengan baja. Menurut perkiraan kasar, nilai kuat tarik beton berkisar antara 9\%-15\% dari kuat tekanya sedangkan daktilitas beton yang rendah dicerminkan oleh kurva load/tegangan-reganganya yang mempunyai penurunan kekuatan tekan yang cepat pada daerah pasca puncak, sehingga menyebabkan keruntuhan secara tiba-tiba. Penambahan bahan tambah berupa serat yang akan dicampurkan ke dalam campuran beton diharapkan 
dapat meningkatkan kuat tarik pada beton serta dapat membuat beton lebih daktail. Bahan-bahan limbah disekitar lingkungan dapat dimanfaatkan sebagai bahan tambah dalam dalam campuran beton. Hal tersebut dapat memberikan alternatif untuk memanfaatkan limbah - limbah yang tidak termanfaatkan, seperti limbah botol plastik High density polyethylene (HDPE).

Khusus mengenai limbah botol plastik, jika diperhatikan lebih lanjut mengenai bahan dasar gelas plastik ini seperti yang tertera pada bagian dasarnya, terdapat tulisan HDPE (high density polyetylene)/ memiliki nomor 2 pada symbol daur ulang, yang berarti bahan dasar gelas plastik ini adalah high density polyetilene. Dengan optimalisasi pemanfaatan limbah botol plastik high density polyethylene ini diharapkan dapat mengurangi limbah yang mencemari lingkungan dan memberikan nilai tambah tersendiri. Dalam penelitian ini cacahan limbah botol plastik high density polyethylene (HDPE) akan didaur ulang menjadi serat yang berfungsi sebagai bahan tambah dalam campuran beton normal. Serat tersebut dicampurkan ke dalam adukan beton dengan persentase penambahan serat yang bervariasi. Dengan penambahan serat tersebut diharapkan dapat memberikan perbaikan terhadap kuat tarik beton serta membuat beton lebih daktail.

Limbah botol plastik high density polyethylene (HDPE) ini tidak dapat langsung digunakan, tetapi harus melalui suatu proses pengolahan, sehingga siap digunakan untuk campuran beton. Proses penggunaan limbah botol plastik high density polyethylene (HDPE) ini diantaranya harus dibersihkan dan diolah terlebih dahulu sehingga menjadi kepingan- kepingan serat high density polyethylene. serat high density polyethylene yang digunakan mempunyai lebar rata-rata $0.50 \mathrm{~cm}$ dan dipotong dengan panjang 2.50 $\mathrm{cm}$. diharapkan dengan dimensi tersebut dalam proses pencampuranya dapat bersifat homogen.

Tujuan dari penambahan serat ke dalam beton adalah untuk menambah kuat tarik beton. Dengan adanya serat, ternyata beton menjadi lebih tahan retak dan tahan benturan, jika masalah penyerapan energi diperlukan. Perlu diperhatikan bahwa pemberian serat tidak banyak menambah kuat tekan beton, namun hanya menambah daktilitas beton (Kasno, 2008).

\section{Beton Serat}

Beton serat adalah beton yang terbuat dari semen Portland atau bahan pengikat hidrolis lainya yang ditambah dengan agregat halus dan kasar, air dan diperkuat dengan serat (Yohanes, et al, 2006).

Dalam pembagian beton serat, jenis beton serat dapat kita bedakan menjadi 2 jenis yaitu beton serat alami dan serat buatan. Serat alam umumnya terbuat dari bermacam-macam tumbuhan, karena sifatnya umumnya mudah menyerap dan melepaskan air, serat alam mudah lapuk sehingga tidak dianjurkan digunakan pada beton bermutu tinggi atau untuk penggunaan khusus. Yang termasuk serat alam antara lain rami, sisal, ijuk, jute, serabut kelapa dan lain-lain. Serat buatan umumnya dibuat dari senyawa-senyawa polimer. Mempunyai ketahanan tinggi terhadap perubahan cuaca, mempunyai titik leleh, kuat tarik, dan kuat lentur tinggi. Digunakan untuk beton bermutu tinggi dan yang akan digunakan secara khusus. (http://Oerleebook.wordpress.com/ 2009/10/28/beton-serat/).

Menurut Suhendro (dalam Ariatama, 2007), beberapa hal yang perlu mendapat perhatian khusus pada beton fiber ini adalah masalah fiber dispersion atau teknik pencampuran adukan agar fiber yang ditambahkan dapat tersebar merata dengan orientasi yang random dalam beton dan masalak kelecakan (workability) adukan. Secara umum dapat dijelaskan dengan memodifikasikan proporsi adukan (misalnya dengan menambahkan superplasticizer ataupun memperkecil diameter agregat). Dan memodifikasi teknik pencampuran adukan (mixing technique) maka masalah fiber dispersion dapat diatasi. Untuk masalah (workability), secara umum dapat pula dikatakan bahwa workability akan menurun seiring dengan makin bertambahnya persentase fiber yang ditambahkan dan makin besarnya rasio kelangsingan fiber.

Keuntungan utama menambahkan serat dalam beton adalah pengurangan retak susut. Beton berserat digunakan dalam beberapa aplikasi misalnya stabilitas kemiringan tanah, perkerasan, panel tembok dan pelat lantai.Juga dapat dipergunakan untuk keperluan arsitektur dan sirap atap, dek jembatan, tangki penyimpanan, lantai parkir dan elemen pracetak (Chandra, 2008).

Menurut Dipohusodo (1999), nilai kuat tekan dan tarik bahan beton tidak berbanding lurus, setiap 
usaha perbaikan mutu kekuatan tekan hanya disertai peningkatan kecil nilai kuat tariknya. Suatu perkiraan kasar dapat dipakai, bahwa nilai kuat tarik bahan beton normal hanya berkisar antara 9\%-15\% dari kuat tekannya. Kuat tarik bahan beton yang tepat sulit untuk diukur. Suatu pendekatan yang umum dilakukan dengan menggunakan modulus of rupture, ialah tegangan tarik lentur beton yang timbul pada pengujian hancur balok beton polos (tanpa tulangan), sebagai pengukur kuat tarik sesuai dengan teori elastisitas.

Menurut Kasno (2008), kuat tarik bahan beton juga ditentukan melalui pengujian split cilinder yang umumnya memberikan hasil yang lebih baik dan lebih mencerminkan kuat tarik yang sebenarnya. Nilai pendekatan yang diperoleh dari hasil pengujian berulang kali mencapai kekuatan 0,50-0,607 fc', sehingga untuk beton normal digunakan nilai $0,57\urcorner \mathrm{fc}^{\prime}$.

\section{Serat High Density Polyethylene}

Menurut Callister W.D (dalam Hariana 2008), polimerisasi yaitu proses perubahan molekul yang lebih sederhana /kecil, atau proses sintesisasi dari molekul polymer yang besar/berat dengan bantuan katalis, yang berfungsi sebagai pemrakarsa (initiator) untuk memulai proses reaksi polimerisasi. Properties atau karakteristik polymer yang terbentuk dapat dimodifikasi dengan penambahan bahan addictive.

Polyethylene digolongkan menjadi polietylene tekanan tinggi, tekanan medium dan tekanan rendah oleh tekanan pada polimerisasinya, atau masing masing menjadi polyethylene masa jenis rendah (LDPE) dengan masa jenis 0,910-0,926, polyethylene masa jenis medium (MDPE dengan masa jenis 0,926-0,940 dan polyethylene masa jenis tinggi (HDPE) dengan masa jenis 0,941 - 0,965, menurut masa jenisnya, karena sifat-sifatnya erat hubunganya dengan masa jenis ( kristalinitas) (Van Vlack, 1995).

HDPE (high density polyetylene) diproduksi dengan reaksi bertekanan rendah antara $5-140 \mathrm{~kg} /$ $\mathrm{cm}^{2}$ dengan temperature berkisar antara $60-300{ }^{\circ} \mathrm{C}$ menggunakan katalis slurry Ziegler-Natta dengan isobutana sebagai pelarut sehingga lebih dikenal dengan proses slurry, selain proses gas maupun fase larutan untuk jenis-jenis polyethylene yang lain. Untuk mengontrol berat molekul yang berhubungan dengan sifat-sifat fisik polyethylene digunakan hydrogen sedang, komonomer a-olefin dapat digunakan untuk mengatur densitasnya (Hariana, 2008). Menurut Van Vlack, (1995) karakteristik HDPE terlihat pada tabel-1.

Tabel 1. Karakteristik serat high density polyetylene

\begin{tabular}{lll}
\hline \multicolumn{1}{c}{ Karakteristik } & \multicolumn{1}{c}{ Unit } & \multicolumn{1}{c}{ Nilai } \\
\hline Berat jenis & $\mathrm{g} / \mathrm{cm}^{3}$ & 0.96 \\
Kristalinitas & $\mathrm{v} / \mathrm{o}$ & $\sim 50$ \\
Muai panas & ${ }^{\circ} \mathrm{C}^{-1}$ & $120 \times 10^{-6}$ \\
Daya hantar panas & $\left(\mathrm{watt} / \mathrm{m}^{2}\right)$ & 0,52 \\
& $\left({ }^{\circ} \mathrm{C} / \mathrm{M}\right)$ & \\
Kekuatan tarik & $\mathrm{MPa}$ & $20-40$ \\
Modulus Young & $\mathrm{MPa}$ & $400-1200$ \\
Ketahanan panas terhadap pemakaian terus & ${ }^{\circ} \mathrm{C}$ & $80-120$ \\
menerus & & \\
Daya hantar 10 menit & ${ }^{\circ} \mathrm{C}$ & $120-125$ \\
\hline
\end{tabular}

Menurut Hariana (2008), HDPE juga lebih keras dan bisa bertahan pada temperatur tinggi (120 $\left.{ }^{\circ} \mathrm{C}\right)$. HDPE sangat tahan terhadap bahan kimia sehingga memiliki aplikasi yang luas, diantaranya: Kemasan deterjen, Kemasan susu, Tanki bahan bakar, Kayu plastik, Meja lipat, Kursi lipat, Kantong plastik, Wadah pengangkut beberapa jenis bahan kimia,sistem perpipaan transfer panas bumi, sistem perpipaan gas alam, pipa air, pembungkus kabel, papan luncur salju.

\section{METODE PENELITIAN}

\section{Lokasi Penelitian}

Pelaksanaan penelitian yang meliputi pemeriksaan serta pengujian bahan, sampai pada tahap pembuatan benda uji dan perawatan dilakukan di Laboratorium Teknologi Beton Jurusan Teknik Sipil Fakultas Teknik Universitas Muhammadiyah Malang. 


\section{Rancangan Penelitian}

Untuk mengetahui sejauh mana pengaruh penambahan cacahan high density polyethylene pada beton normal, maka dilakukan pengujian terhadap kuat tarik beton. Penelitian ini menggunakan campuran beton dengan $F c^{\prime}=20$

Tabel 2. Rancangan Benda Uji

\begin{tabular}{cccc}
\hline Variasi serat & Berat $(\mathrm{kg})$ & Bentuk benda uji & Jumlah \\
\hline $0 \%$ & 0 & Silinder & 3 \\
$1 \%$ & 0.15 & Silinder & 3 \\
$2 \%$ & 0,31 & Silinder & 3 \\
$3 \%$ & 0,46 & Silinder & 3 \\
$4 \%$ & 0,61 & Silinder & 3 \\
$5 \%$ & 0,77 & Silinder & 3 \\
$6 \%$ & 0,92 & Silinder & 3 \\
$7 \%$ & 1,08 & Silinder & 3 \\
$8 \%$ & 1,23 & Silinder & 3 \\
$9 \%$ & 1,38 & Silinder & 3 \\
$10 \%$ & 1,54 & Silinder & 3 \\
\hline \multicolumn{4}{c}{ Jumlah total benda uji } \\
\hline
\end{tabular}

\section{Bahan, Peralatan dan Alur Penelitian}

Material-material yang digunakan pada penilitian ini adalah semen, agregat kasar, agregat halus, air, serat HDPE berbentuk pipih yang mempunyai ukuran panjang $2,5 \mathrm{~cm}$ serta lebar 0,5
$\mathrm{MPa}$, jumlah serat yang digunakan berdasarkan fraksi volume sehingga kadar variasi serat akan sangat dipengaruhi oleh berat jenis plastik. Berat jenis plastik yang didapat dari literatur adalah 960 $\mathrm{kg} / \mathrm{m}^{3}$, benda uji yang mengandung bahan tambah berupa serat high density polyethylene dengan 11 variasi serat yang dapat dilihat pada tabel-2.

$\mathrm{cm}$. Sedangkan alat-alat yang digunakan adalah peralatan pemeriksaan bahan, mesin aduk beton, peralatan pemeriksaan slump beton, cetakan benda uji, alat uji tarik belah beton. Tahapan penelitian yang dilakukan terlihat pada bagan alir penelitian seperti pada Gambar-1.

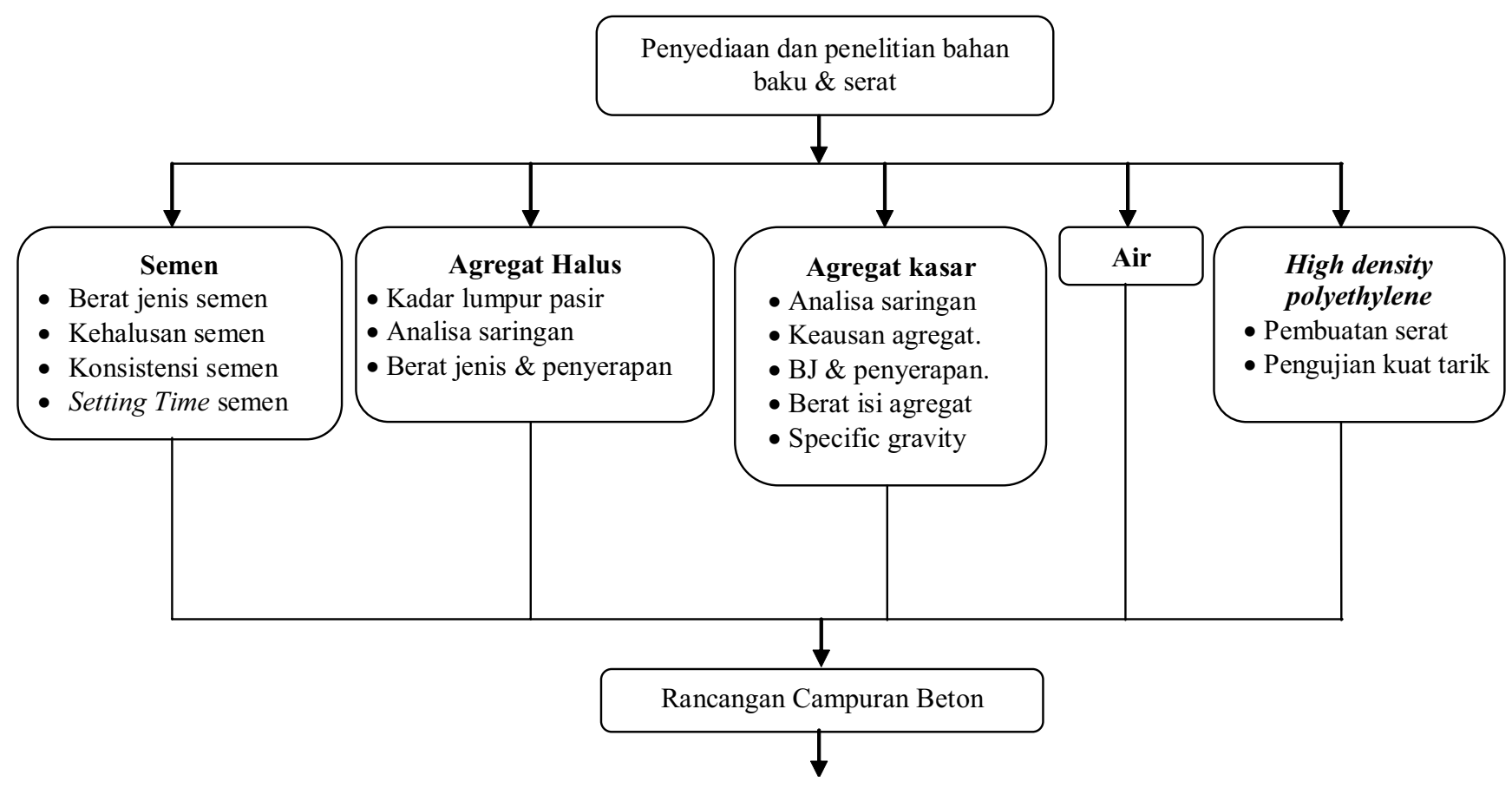




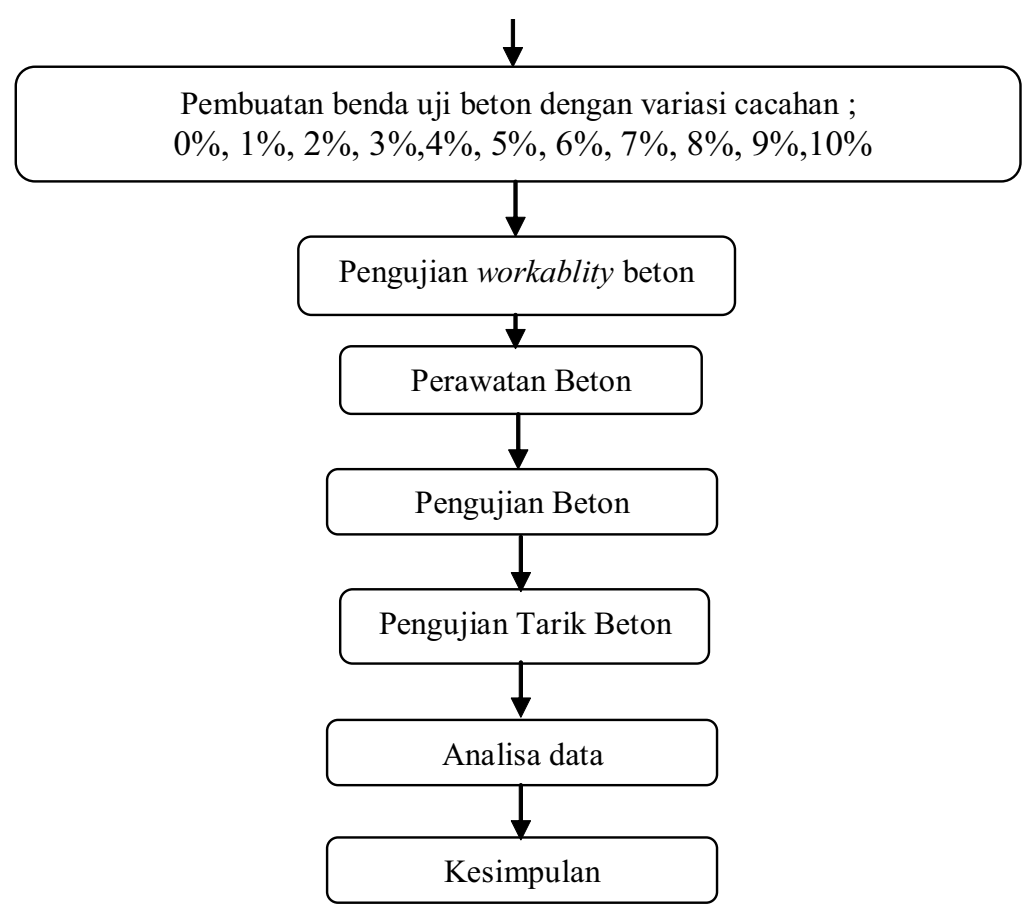

Gambar 1. Bagan alir Penelitian

HASIL DAN PEMBAHASAN

\section{Workability beton}

Untuk mengetahui pengaruh penambahan serat pada kemudahan pengerjaan beton atau tingkat workability beton dilakukan pengujian slump test saat pengadukan beton segar Pengambilan nilai slump dilakukan untuk setiap penambahan serat beton, mulai $1 \%$ sampai $10 \%$. Dalam analisa akan dilihat pengaruh adanya penambahan bahan tambah berupa serat HDPE dalam adukan beton terhadap tingkat kemudahan pengerjaan (workability). Nilai target rencana slump adalah $100 \pm 20 \mathrm{~mm}$. Hasil uji nilai slump dapat dilihat pada Gambar-1.
Hasil penelitian menunjukkan bahwa penambahan jumlah serat HDPE dalam adukan beton akan membuat nilai slump cenderung menurun hal ini terjadi karena dengan jumlah pasta semen (jumlah air semen) yang tetap namun terjadi penambahan bahan yang dapat mengurangi keenceran (menambah kekentalan) adukan beton .

Dengan semakin menurunya nilai slump menunjukan bahwa bilamana bahan tambah ini dicampurkan dalam adukan beton dengan persentase bahan tambah yang meningkat, maka akan semakin menyulitkan dalam pekerjaan hal ini bisa berakibat pada peningkatan jumlah rongga udara pada benda uji , karena tahap pemadatan yang sulit dilakukan tetapi hal ini bisa diatasi dengan cara menggunakan vibrator pada saat pemadatan.

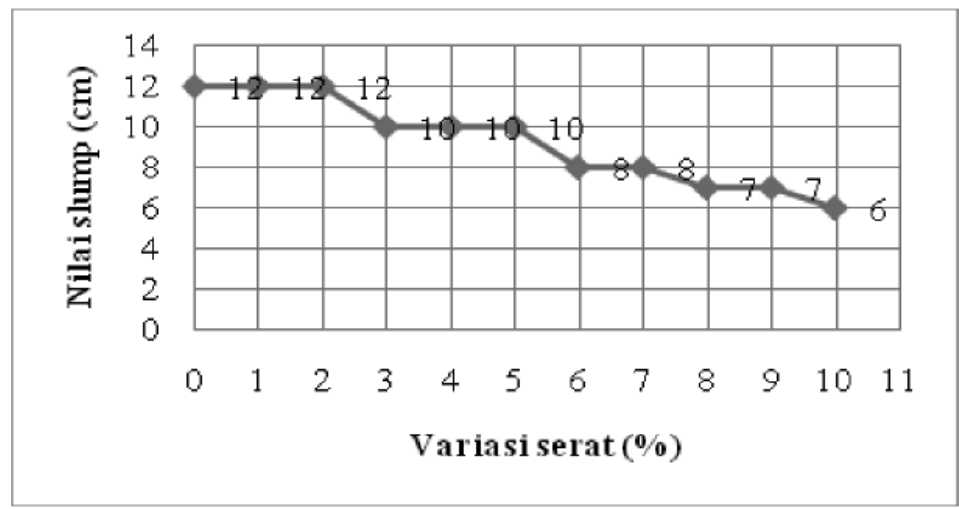

Gambar 2. Hubungan nilai slump dengan jumlah serta pada beton segar 


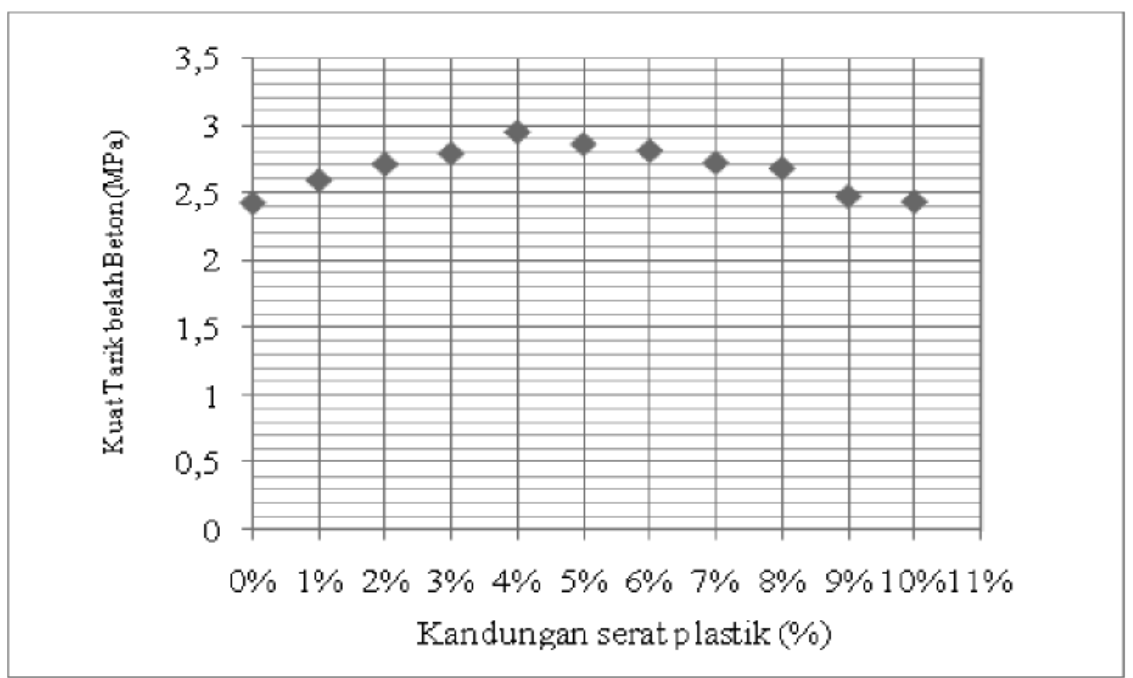

Gambar 3. Hubungan Kuat Tarik Beton dengan Jumlah Serat

\section{Kuat Tarik Beton}

Pengujian kuat tarik belah beton dilaksanakan setelah benda uji pada umur 28 hari. Pengujian kuat tarik belah beton dilakukan untuk memperoleh nilai kuat tarik belah beton dengan adanya perbedaan variasi penambahan serat high density polyethylene. Hasil uji kuat tarik beton rata-rata dengan berbagai variasi penambahan serat HDPE dapat dilihat pada Gambar-3.

Gambar-3 menjelaskan bahwa penambahan serat HDPE pada campuran beton dapat meningkatkan kuat tarik belah beton. Semakin besar persentase kadar variasi serat maka kuat tarik belah akan semakin tinggi, tetapi pada suatu titik optimal selanjutnya kuat tarik belah beton akan menurun. dari hasil perhitungan kuat tarik diperoleh nilai kuat tarik rata-rata beton normal sebesar 2,42 $\mathrm{MPa}$ dan kuat tarik beton berserat HDPE optimum sebesar 2,86 $\mathrm{MPa}$ dengan presentase penggunaan serat HDPE sebesar 4\% serta peningkatan kekuatan sebesar 18\%. Peningkatan ini dikarenakan faktor Penambahan serat kedalam adukan beton akan menambah ikatan didalam beton yang dapat memperkecil terjadinya retakan-retakan akibat pembebanan dan beton tidak mudah hancur akibat pembebanan.

Kemudian untuk kadar serat 6\% dan $10 \%$ tampak bahwa beton mulai mengalami penurunan kuat tarik belah secara berturut penurunan kuat tarik paling minimum yaitu sebesar 2,43 MPa. Namun nilai tersebut masih lebih tinggi dari beton normal. Hal ini disebabkan oleh berkurangnya workability campuran, sehingga mengakibatkan sulitnya pemadatan adukan efek dari sulitnya dilakukan pemadatan akan menimbulkan banyak pori-pori beton akibat udara yang terperangkap, Pori tertersebut menjadi titik lemah saat menerima beban tarik .

Disamping itu, yang lebih penting adalah mekanisme keruntuhan pada pengujian tarik tersebut berubah drastis dari bersifat brittle (getas) untuk beton biasa dan untuk beton yang ditambahkan serat HDPE beton menjadi lebih daktail dimana pada saat beban puncak beton yang diberi serat HDPE tidak terjadi pembelahan secara tiba-tiba.

\section{Pola Penyebaran Serat}

Pola penyebaran serat high density polyethylene yang dipakai dalam penelitian ini adalah pola penyebayan serat secara acak. Berikut adalah gambar pola penyebaran serat high density polyethylene dengan variasi $1 \%$ hingga $10 \%$. 


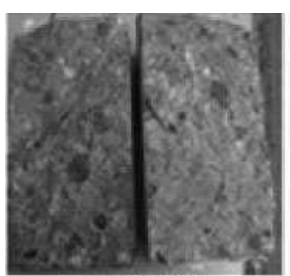

serat $1 \%$

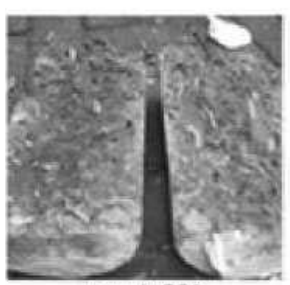

serat $6 \%$

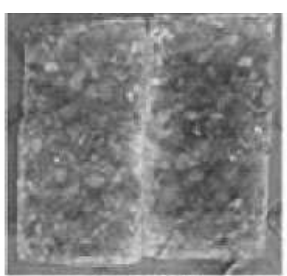

serat $2 \%$

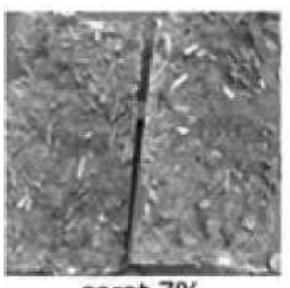

serat $7 \%$

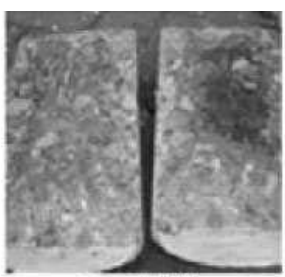

serat 3\%

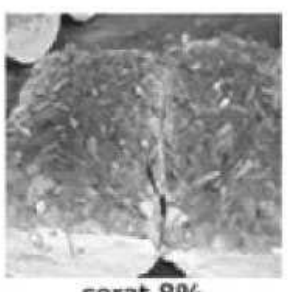

serat $8 \%$

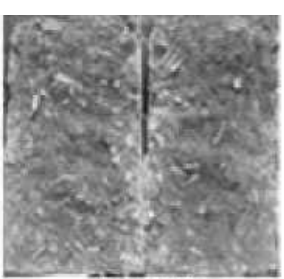

serat $4 \%$

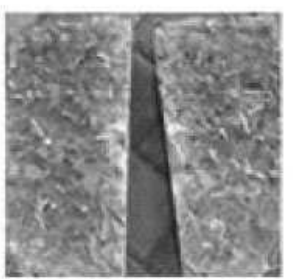

serat $9 \%$

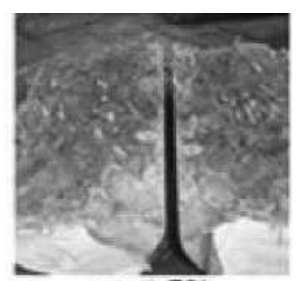

serat $5 \%$

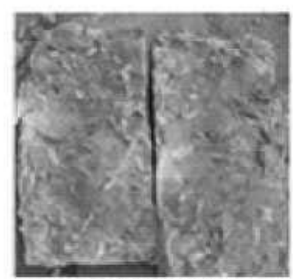

serat $10 \%$

Gambar 4. Pola Penyebaran Serat pada benda uji

Gambar-4 memperlihatkan bahwa serat tersebar secara acak di dalam beton pada berbagai variasi jumlah serat yang diberikan pada beton. Sebaran acak serat didalam beton memiliki orientasi arah serat yang sangat bervariasi, tidak terlihat adanya serat yang menggumpal. Semakin bertambah variasi kadar serat yang ditambahkan terlihat serat mengarah pada arah vertikal, dimana arah ini sangat menguntungkan untuk meningkatkan daktilitas beton karena beton tidak akan terbelah secara tiba-tiba pada saat tercapai beban puncak.

\section{KESIMPULAN DAN SARAN}

Pemakaian serat HDPE pada beton dapat meningkatkan kuat tarik beton sampai $18 \%$ dibandingkan dengan beton tanpa serat (beton konvensional) dengan kuat tarik terbesar diperoleh sebesar 2,86 MPa pada pemakaian 4\% serat HDPE.

Pemakaian serat HDPE juga mempengaruhi workability dari beton, dimana makin banyak penggunaan serat pada beton akan mengakibatkan menurunnya tingkat workability beton atau beton makin sulit untuk diaduk dan dihamparkan dengan baik, hal ini ditunjukkan dengan penurunan nilai slump.

Penyebaran serat HDPE pada beton sangat dipengaruhi bagaimana proses pencampuran dilakukan saat pengecoran beton. Untuk memperoleh penyebaran serat secara acak dan merata maka serat plastik HDPE diberikan pada bagian akhir dari pengadukan beton dan dilakukan dengan melewatkan melalui saringan pada ketinggian tertentu.

\section{DAFTAR PUSTAKA}

Anonim, SNI 03-2834-2000 Tata Cara Pembuatan Rencana Campuran Beton Normal, BSN Jakarta

Ariatama, A, 2007, Pengaruh Pemakaian Serat Kawat Berkait Pada Kekuatan Beton Mutu Tinggi Berdasarkan Optimasi Diameter Serat, Tesis Magister Teknik sipil, Universitas Diponegoro Semarang : Tidak diterbitkan.

Chandra, J, 2008 "Pengaruh pemakaian cacahan limbah gelas plastik polypropylene( $p p)$ pada kuat tarik dan kuat lentur material beton”, Skripsi Teknik sipil, Universitas Indonesia Jakarta : Tidak diterbitkan.

Dipohusodo, Istimawan, 1999, Struktur Beton Bertulang, Gramedia, Jakarta.

Hariana A, 2008 "Studi karakteristik agregat kasar ringan buatan dari limbah botol plastik high density polyethylene (HDPE) dan pengaruhnya terhadap sifat-sifat mekanis beton ringan". Skripsi Teknik sipil, Universitas Indonesia Jakarta : Tidak diterbitkan.

Kasno, 2008 "Pengaruh Penambahan Serat Baja pada Campuran Beton”. Skripsi Teknik sipil, Universitas Negri Semarang: Tidak diterbitkan.

Oerleebook.com. Beton Serat "www.oerleebook.com.beton-serat.

Van Vlack, Lawrence ,1995, Ilmu Dan Teknologi Bahan (Ilmu Logam Dan Bukan Logam). 
edisi kelima, diterjemahkan oleh:Djaprie, Sriati, Penerbit Erlangga Jakarta

Yohanes L.D. Adianto, et al, 2006, "Penelitian pendahuluan Hubungan Penambahan serat Polymeric terhadap Karakteristik Beton Normal", Jurnal Teknik Sipil, Program Studi Teknik Sipil Universitas Katolik Parahyangan Bandung, Volume 8, No.1,34-40, Maret:1410-9530. 